\title{
Oral Health Literacy among Caregivers in Bangalore City, India
}

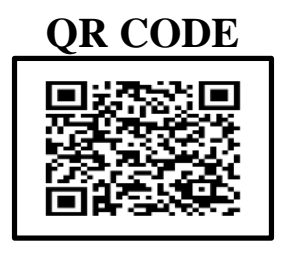

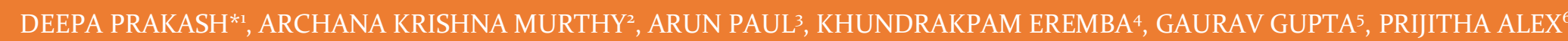

INTRODUCTION: Oral health literacy is found to be one of the determinant to individuals health, health behaviour and health outcomes. Individuals with lower literacy have poorer health knowledge, unhealthy behaviour, less use of health services, increased rate of hospital administration, increased health care costs and poor health outcomes.

AIM: To assess caregiver's oral health literacy of children aged 3-6 years in Bangalore city.

MATERIALS AND METHODS: A cross-sectional study was conducted on 635 child/caregiver dyads from a sample of children aged 3-6 years who were selected from anganwadis and preschools in Bangalore city. Demographic details were collected using structured questionnaire. Caregiver literacy was measured using the Rapid Estimate of Adult Literacy in Dentistry (REALD-30).

RESULTS: Among 635 child/caregiver dyads, caregiver's and children's mean ages were 33.45 years(SD = 3.36) and 5.28 years (SD =0.67), respectively. The mean literacy score was $14.25(\mathrm{SD}=7.67)$. The results also indicated that there was an association between sociodemographic variables such as age, education, income, occupation, socioeconomic status and caregivers' oral health literacy. CONCLUSION: Caregiver's oral health literacy is influenced by sociodemographic factors. Oral health literacy is potential determinant and as impact on oral health outcomes in young children.

KEYWORDS: Oral Health Literacy, Caregivers, Health Information, Oral Health

\section{INTRODUCTION}

In recent times, literacy has emerged as a prime item on the research syllabus in the field of medicine and public health. ${ }^{1}$ Health literacy is increasingly described as a method, non-pharmacological in nature, for management and prevention of diseases and also currency for improving the quality of health and health care. Basic health knowledge is in need in order to have a healthy life. ${ }^{2}$

Health literacy is defined as the "degree to which individuals have the capacity to acquire, exercise, and perceive basic health information and services needed to frame significant health decisions". Health literacy is not only associated with the ability to write or read the English language, but is also affected by education, culture and the context of the situation. The ability to perceive health information and acquire services is vital for management of personal health; therefore, health literacy is acknowledged as a critical element of health. ${ }^{3}$

Health literacy, along with general literacy, is an essential health determinant. ${ }^{4}$ Thus, the meaning of health literacy is much more than the mere capability of reading leaflets or brochures and arranging appointments. By enhancing people's access to health related knowledge and services, and their extent to utilize it efficiently, health literacy authorisation is of prime importance. Health literacy is reliant upon basic grades of literacy. Poor literacy can have direct influence on people's health by restricting their personal, social and cultural evolution, as well as impeding the blossoming of health literacy. ${ }^{5}$

Even people with sufficient literacy competence may find interpreting healthcare information a challenging task. They may not be able to comprehend basic terminology and the concepts of health and medical field. ${ }^{6}$ The susceptibility to make medication errors is more in people with poor health literacy, and they have worse health status, poor quality of life, more rate of hospital admissions, and much more estimated healthcare expenses than people with adequate knowledge of health related facts. Health literacy expertise is critical for warranting people's capability to develop and upgrade their health status. ${ }^{7}$

Disparity and variation in oral health status and its related quality of life may result from countless hurdles extending from individual, familial, environmental, socio-economic, biological, psychological, cultural and political factors. Restricted access to oral health care utilities and services, complicated oral health care policies and systems, a lack of oral-health education material and poor oral heath literacy are also major 
barriers to public health. ${ }^{8}$

The procedure of obtaining oral health education and information, appraising its fundamentals and applying preventive and treatment plans for caring oral health adequately and timely requires new skill inculcation known as oral health literacy (OHL). ${ }^{9}$ Oral health literacy is an interactive equilibrium between cultural and social determinants, the health and education framework, language and oral health consequences predicting that it may be a new facet of oral health and should be appraised more diligently in research related to oral sciences. ${ }^{10}$

Although current literature unveils that oral health literacy is co-related with the grades of education, ethnicity, utilization of dental services, oral health education, and oral care practices, but data and statistics about the impression of oral health literacy on oral health outcomes and quality of life are meagre. ${ }^{8}$ There are numerous factors which directly influence the low health literacy levels in the community such as difficulty in navigating the health care system; increased risk of hospital admissions and emergency

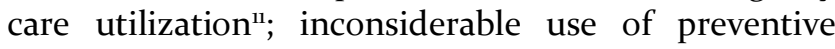
strategies (fluoride dentifrices, screening of paediatric patients $)^{12}$; difficulty in understanding and completion of documents and consent formalities; inability to read instructions for prescribed medications ${ }^{13}$; use of more priced services; medications abuse and misuse; misunderstanding of self-care instructions and practice of inappropriate and inadequate preventive health care. ${ }^{14-16}$ Other factors that can be added to this list are depressive disorders due to misunderstanding of one's disease conditions; increased utilization of specialty care; increased need for health care professionals; and poor response in health care research and surveys. ${ }^{17}$

Poor health literacy is regarded as a risk factor of poor oral health status in an individual, sub-standard heath outcomes at community level and health discrepancies and disparities. The overall major outcome is the high cost as the patients with relatively lower health literacy level are more prone to use more health care resources than those with favourable literacy competencies. ${ }^{18}$ Therefore, the aim of this study was to assess oral health literacy levels in caregiver's of children aged 3-6 years in Bangalore city.

\section{MATERIALS AND METHODS}

This cross-sectional study was conducted to assess oral health literacy levels in caregiver's of children aged 3-6 years in Bangalore city. The approval of this study was obtained from the Institutional Review Board of The Oxford Dental College and Hospital, Bangalore. Eligibility criteria included Caregivers of children aged between 3-6 years studying in anganwadis and preschools in Bangalore city, Caregivers who had received formal education of up to 12th standard in English medium. Caregivers with cognitive impairment, vision or hearing disorders were excluded from the study.

A multi-stage cluster random sampling method was used to collect the data. After written consent for study participants was obtained, eligible caregivers were asked to complete verbally administered surveys by trained interviewer in personal presence. To assess the education, income, occupation and socio-economic status of the caregiver, modified Kuppuswamy's scale was used. ${ }^{19}$

Caregiver's oral health literacy was evaluated by using the Rapid Estimate of Adult Literacy in Dentistry (REALD-30). ${ }^{20}$ This previously validated tool includes 30 words from the dentistry context that are arranged in order of increasing difficulty. This instrument is used to assess reading ability in the health context and does not allow assessment of the entire broad context of "health literacy," which can include health-related knowledge, behaviours, and ability to process information from other media such as oral literacy. With the REALD- 30, the words are read aloud by the caregiver to the interviewers. As REALD-30 is a wordrecognition test, participants were asked to skip, rather than trying to pronounce the words when they did not know about the used word. For scoring the REALD-30, 1 point is allocated for each word that is pronounced correctly, and then the points are totalled to get an overall score. The total score has a probable range varying from o (lowest literacy) to 30 (highest literacy). The Cronbach's $\alpha$ for REALD-30 was assessed to be 0.87 . No practical norms have been established till date to denote a score for "adequate" OHL. As in a previous investigatory research, an arbitrary cut off of $<13$ was considered to indicate "low" OHL and $>13$ to indicate high oral health literacy. ${ }^{21}$

Statistical Analysis: In the present study, descriptive statistical analysis was carried out and the results on continuous measurements were presented as Mean and standard deviation (SD) and outcomes on categorical measurements were presented in Number (\%). A Significance level of $5 \%$ was used for assessment 
Analysis of variance (ANOVA) was used to find the level of significance of study parameters between three or more group of patients and Student t test (two tailed, independent) was used to find the significance of study variables on continuous scale between two groups (Inter group analysis) on metric parameters.

\section{RESULTS}

A total of 635 female caregivers from Anganwadi centres and private preschool participated in the study. Table 1 summarizes the socio-demographic characteristics of the study participants. The age of the subjects ranged between 27-36 years with mean age of $33.45 \pm 3.36$ years. Educational qualification distribution showed $224(35.2 \%)$ of caregivers had intermediate education, $316(49.8 \%)$ caregivers reported of having Graduate or post graduate education and majority 95 (15\%) had professional education. The majority of the participants $279(43.9 \%)$ belonged to upper middle class.

Table 2 shows the distribution of caregivers based on their ability to read REALD-30 words. The mean REALD score was 14.25 \pm 7.67 with range of 3-25.

Table 3 shows the mean oral health literacy according to different variables (age, education, occupation, income and socioeconomic status).Using ANOVA the mean difference in the mean literacy score about caregiver's education, occupation, income and SES were found to be significantly associated. Further using Tukey's post hoc test it was found that caregivers who had professional education had significantly higher mean literacy $24.2 \pm 1.22$ when compared intermediate and graduate or post graduate education group. Similarly caregivers who were professionals had significantly higher mean literacy score of $22.83 \pm 2.58$ when compared to unemployed, unskilled, semi-skilled and skilled group). It was also found that caregivers who had income of $>$ Rs3o, 375 had significantly higher mean literacy score of $22.08 \pm 2.83$ compared to other income groups. Also, Caregivers who fall into Upper class of SES had significantly higher mean literacy score compared to upper and lower middle groups.

\section{DISCUSSION}

Health Literacy is known moderator between socioeconomic factors, health behaviour and oral health outcomes in differing communities, describing multivariable generalisation of the derivatives in oral health and outcomes. In the present study, majority $(85.7 \%)$

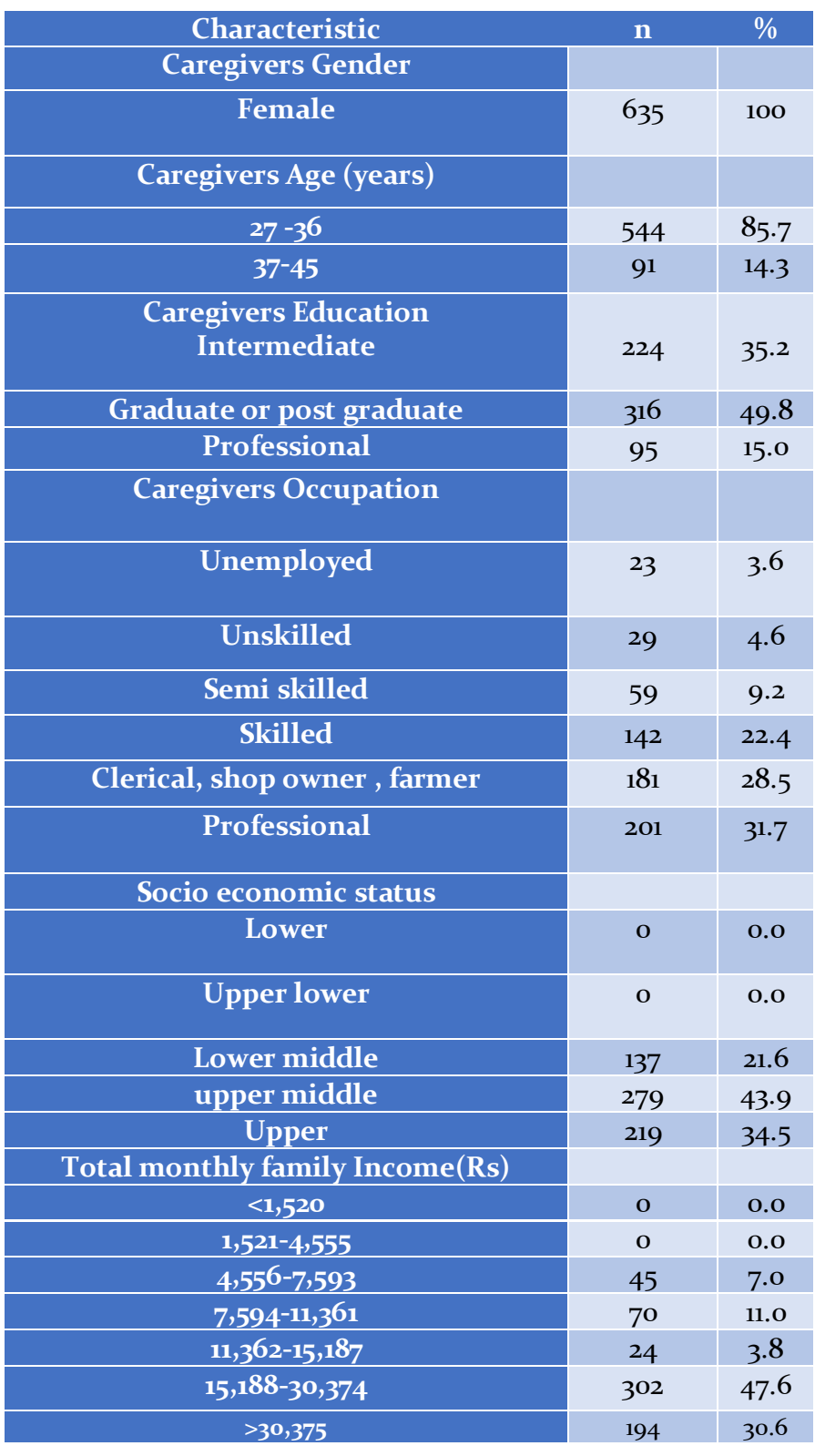

Table 1. Sociodemographic characteristics of the participants

female caregivers of belonged to age group of 27-36 years with mean age of $33.45 \pm 3.36$ years which was similar to results reported in research work conducted by Lee et al. ${ }^{20}$, Schroth et al. ${ }^{22}$ Susan Bridges et al. ${ }^{23} \mathrm{~S}$ Parthasarathy et al. ${ }^{24}$ and Arthi Veerasamy et al. ${ }^{25}$

Although meagre research has been conducted to inspect oral health literacy (OHL) levels, adequate rationalization exists for pursuing research in this horizon. In the present study, the mean OHL of the 


\begin{tabular}{|c|c|c|c|c|}
\hline \multirow{3}{*}{ REALD-30 words } & \multicolumn{4}{|c|}{ Ability to read } \\
\hline & \multicolumn{2}{|c|}{ Yes } & \multicolumn{2}{|c|}{ No } \\
\hline & $\mathbf{n}$ & $\%$ & $\mathbf{n}$ & $\%$ \\
\hline Sugar & 635 & 100 & 0 & o \\
\hline Smoking & 635 & 100 & o & o \\
\hline Floss & 635 & 100 & o & o \\
\hline Brush & 632 & $99 \cdot 5$ & 3 & 0.5 \\
\hline Pulp & 354 & $55 \cdot 7$ & 281 & $44 \cdot 3$ \\
\hline Fluoride & 308 & 48.5 & 327 & 51.5 \\
\hline Braces & 481 & $75 \cdot 7$ & 154 & $24 \cdot 3$ \\
\hline Genetics & 421 & 66.3 & 214 & 33.7 \\
\hline Restoration & 313 & $49 \cdot 3$ & 322 & 50.7 \\
\hline Bruxism & 219 & $34 \cdot 5$ & 416 & $65 \cdot 5$ \\
\hline Abscess & 425 & 66.9 & 210 & 33.1 \\
\hline Extraction & 364 & $57 \cdot 3$ & 271 & 42.7 \\
\hline Denture & 405 & 63.8 & 230 & 36.2 \\
\hline Enamel & 133 & 20.9 & 502 & 79.1 \\
\hline Dentition & 384 & 60.5 & 251 & $39 \cdot 5$ \\
\hline Plaque & o & o & o & o \\
\hline Gingiva & 27 & $4 \cdot 3$ & 608 & $95 \cdot 7$ \\
\hline Malocclusion & 214 & 33.7 & 421 & 66.3 \\
\hline Incipient & 312 & 49.1 & 323 & 50.9 \\
\hline Caries & 298 & 46.9 & 337 & 53.1 \\
\hline Periodontal & 199 & 31.3 & 436 & 68.7 \\
\hline Sealant & 311 & 49.0 & 324 & 51 \\
\hline Hypoplasia & 161 & 25.4 & 474 & 74.6 \\
\hline Halitosis & 154 & $24 \cdot 3$ & 481 & $75 \cdot 7$ \\
\hline Analgesia & 269 & 42.4 & 366 & 57.6 \\
\hline Cellulitis & 361 & 56.9 & 274 & 43.1 \\
\hline Fistula & 375 & 59.1 & 260 & 40.9 \\
\hline Temporomandibular & 26 & 4.1 & 609 & $95 \cdot 9$ \\
\hline Hyperemia & o & o & o & o \\
\hline Apicoectomy & o & o & o & o \\
\hline Mean literacy score & & & & \\
\hline
\end{tabular}

Table 2. Distribution of caregivers based on their ability to read REALD-30 words

caregivers was 14.25 $(\mathrm{SD}=7.67)$. Although no cut-off points have yet been acclaimed for the REALD-30 to indicate what score would denote inadequate OHL, this approximation is lower than what has been previously concluded in other investigatory studies using the same instrument. Using REALD- 30, Jones and colleagues26 inspected the OHL literacy levels among patients visiting a private dental office and reported a mean 23.9 $(\mathrm{SD}=1.3)$. Lee and colleaguesso explored OHL levels amongst the patients in an outpatient medical facility using the same instrument, reporting a mean score of $19.8(\mathrm{SD}=6.4)$, Miller and colleagues27 reported a mean score of $20.7(\mathrm{SD}=5.5)$ among a sample seeking dental care in a university setting. Recently Susan Bridges et al23 and S Parthasarathy et al24 reported a mean score of $23(\mathrm{SD}=3.9)$.

There are numerous potential explanatory facts behind these reported differences. First, unlike the present study, the three aforementioned ones relied upon 


\begin{tabular}{|c|c|c|c|}
\hline \multirow{2}{*}{ Variables } & \multirow{2}{*}{$\begin{array}{l}\text { No. of } \\
\text { caregivers }\end{array}$} & \multicolumn{2}{|c|}{ REAL D score } \\
\hline & & Mean \pm SD & $P$ value \\
\hline \multicolumn{4}{|l|}{ CG-Age in years } \\
\hline - $\quad 27-36$ & $544(85 \cdot 7)$ & $15.21 \pm 7.66$ & \multirow[t]{2}{*}{$<0.001^{* *}$} \\
\hline - $\quad 37-45$ & $91(14.3)$ & $8.55 \pm 4.69$ & \\
\hline \multicolumn{4}{|l|}{ CG-Education } \\
\hline $\begin{array}{l}\text { - Intermediate or post high school } \\
\text { diploma }\end{array}$ & $224(35.2)$ & $5.23 \pm 1.43^{\mathrm{a}}$ & \multirow[t]{3}{*}{$<0.001^{* *}$} \\
\hline - Graduate or post graduate & $316(49.8)$ & $17.65 \pm 4.11^{\mathrm{a}}$ & \\
\hline - $\quad$ Professional or honors & $95(15)$ & $24.24 \pm 1.22^{\mathrm{a}}$ & \\
\hline \multicolumn{4}{|l|}{ CG-Occupation } \\
\hline - Unemployed & $23(3.6)$ & $6.09 \pm 2.04^{\mathrm{a}}$ & \multirow[t]{6}{*}{$<0.001^{* *}$} \\
\hline - Unskilled & $29(4.6)$ & $6.83 \pm 1.81^{b}$ & \\
\hline - $\quad$ Semi skilled & $59(9.2)$ & $6.39 \pm 3.47^{c}$ & \\
\hline - $\quad$ Skilled & $142(22.4)$ & $6.73 \pm 3.47^{\mathrm{d}}$ & \\
\hline - $\quad$ Clerical, shop owner, farmer & $181(28.5)$ & $15 \cdot 43 \pm 4 \cdot 44^{\mathrm{a}, \mathrm{b}, \mathrm{c}, \mathrm{d}}$ & \\
\hline - $\quad$ Profession & $201(31.7)$ & $22.83 \pm 2.5^{8 \mathrm{a}, \mathrm{b}, \mathrm{c}, \mathrm{d}}$ & \\
\hline \multicolumn{4}{|l|}{ CG-Income } \\
\hline - $\quad<1520$ & o & - & \multirow[t]{7}{*}{$<0.001^{* *}$} \\
\hline - $\quad 1521-4555$ & o & - & \\
\hline - $\quad 4556-7593$ & $45(7)$ & $5.07 \pm 1.54^{\mathrm{a}}$ & \\
\hline - 7594-11361 & $70(11)$ & $5 \cdot 93 \pm 3 \cdot 35^{\mathrm{b}}$ & \\
\hline - $\quad 11362-15187$ & $24(3.8)$ & $5.92 \pm 2.06^{c}$ & \\
\hline - 15188-30374 & $302(47 \cdot 6)$ & $13.18 \pm 6.37^{\mathrm{a}, \mathrm{b}, \mathrm{c}}$ & \\
\hline - $\quad>30375$ & $194(30.6)$ & $22.08 \pm 2.83^{a, b, c}$ & \\
\hline \multicolumn{4}{|l|}{ SES } \\
\hline - Lower & o & - & \multirow[t]{5}{*}{$<0.001^{* *}$} \\
\hline - $\quad$ Lower upper lower & o & - & \\
\hline - $\quad$ Lower middle & $137(21.6)$ & $6.04 \pm 2.70^{a}$ & \\
\hline - $\quad$ Middle upper middle & $279(43.9)$ & $11.85 \pm 5.81^{a}$ & \\
\hline - Upper & $219(34.5)$ & $22.40 \pm 2.47^{\mathrm{a}}$ & \\
\hline
\end{tabular}

Table 3. Distribution of caregivers according age, education, occupation, income, SES with mean REALD -30 score

patient data obtained from dental and medical clinics. It is possible that these patients were higher users of health care, and being able to navigate the health system and access care had higher OHL. These patients may be different from those who have not sought medical/dental care previously and thus may be more informed about oral health. Second, in the present study, the study sample was taken from a heterogeneous population of all categories of SES from preschools and anganwadis who were eligible after meeting the criteria.

In the present study, bivariate analysis of the oral health literacy score with socio demographic variables indicated that gender, income, education and occupation were strongest determinants of oral health literacy. Caregivers with professional education and who were in professional occupation had higher mean 
oral health literacy scores when compared to their counterparts. Categories among income groups suggested that caregivers with income greater than Rs 30,375/- had high oral health literacy compared to others. These results were similar to studies conducted by Lee et al2o Miller et al. ${ }^{27}$ and Arthi Veerasamy et al. ${ }^{25}$ Evidence shows that lower SES population tend to have lower literacy scores. This may be due to fact that people with lower education level receive health information from radio or television rather than print media or the internet. Caregivers with lower SES group are less likely to access health care related services for their children due to inadequate awareness about diseases.

The identification of caregivers with low oral health literacy would be of great help in intimating health care professionals regarding the possibility of these families having difficulty with printed form of media and educational materials. The caregivers who obtain a poor score in a health literacy test may also have issues with communication gap between them and oral healthcare education providers. There is a need to identify common obstacles followed by formulation and inculcation of extra-special attempts to develop culturally sensitive, user-friendly and uncomplicated educational multimedia demonstrating health instructions, involving healthcare professions, healtheducators and promoters for removing the communication gap between them and people with low dental health literacy rates, thus improvising the communication potential of healthcare providers. ${ }^{28}$

\section{REFERENCES}

1. Audrey M D'Cruz, M R Shankar Aradhya. Health literacy among Indian adults seeking dental care. Dent Res J. (Isfahan) 2013; 10(1):20-4.

2. Nutbeam D. The evolving concept of health literacy. Soc Sci Med. 2008 Dec; 67(12):2072-8.

3. Horowitz AM1, Kleinman DV. Oral health literacy: The new imperative to better oral health. Dent Clin North Am 2008;52(2):333-44.

4. Kickbusch IS. Health literacy: Addressing the health and education divide. Health Promot Int 2001; 16(3):289-97.

5. Sarbadhikari SN. How to make healthcare delivery in India more "informed". Educ Health (Abingdon) 2010;23(2):456.

6. Wolf MS, Gazmararian JA, Baker DW. Health literacy and health risk behaviours among older adults. Am J Prev Med 2007;32(1):19-24.
7. Weiss BD, Mays MZ, Martz W, Castro KM, De Walt DA, Pignone MP et al. Quick assessment of literacy in primary care: the newest vital sign. Ann Fam Med 2005 ;3(6):514-22.

8. Naghibi Sistani MM, Yazdani R, Virtanen J, Pakdaman A, Murtomaa H. Determinants of oral health: does oral health literacy matter? ISRN Dent 2013;249591.

9. Horowitz A M, Kleinman DV. Oral health literacy: A pathway to reducing oral health disparities in Maryland. J Public Health Dent 2012; winter; 72 Suppl 1:S26-30.

10. Hongal S, Torwane NA, Goel P, Chandrashekar BR, Jain M, Saxena E. Assessing the oral health literacy: A review. Int J Med Public Health 2013;3:219-24.

11. Howard DH, Gazmaraian J, Parker R. The impact of low health literacy on the medical costs of medicare managed care enrollees. Am J Med 2005; 118 (4):371-7.

12. Bennett IM, Chen J, Soroui JS, White S. The contribution of health literacy to disparities in selfrated health status and preventive health behavior in older adults. Ann Fam Med 2009; May-Jun; 7(3):204-11. 13. Kripalani S, Henderson LE, Chiu EY, Robertson R, Kolm P, Jacobson TA. Predictors of medication selfmanagement skill in a low-literacy population. J Gen Intern Med. 2006;21(8):852-6.

14. Quandt SA, Chen H, Bell RA, Anderson AM, Savoca MR, Kohrman T et al. Disparities in oral health status between older adults in a multiethnic rural community: The rural nutrition and oral health study. J Am Geriatr Soc 2009;57(8):1369-75

15. Kutner ME, Greenberg D, Jin Y, Christine Paulsen. The health literacy of America's adults: results from the 2003 national assessment of adult literacy. Washington, DC: National Center for Education Statistics, US Department of Education; 2006.Available from: http://www.nces.ed.gov/pubs2006/2006483 1.pdf

[Accessed on 2017 Feb 14].

16. Eckman MH, Wise R, Leonard AC, Dixon E, Burrows C, Khan F, et al. Impact of health literacy on outcomes and effectiveness of an educational intervention in patients with chronic diseases. Patient Educ Couns 2012; 87(2):143-51.

17. Hussey LC. Minimizing effects of low literacy on medication knowledge andcompliance among the elderly. Clin Nurs Res 1994; 3(2):132-45.

18. Eagle L, Reid J, Hawkins J, Styles E. Breaking through the invisible barrier of low functional health literacy: Implications for health communication. Stud Commun Sci2005; 5:29-56.

19. Kumar N, Gupta N, Kishore J. Kuppuswamy's 
socioeconomic scale: Updating income ranges for the year 2012. Indian J Public Health 2012; 56:103.

20. Lee JY, Rozier RG, Lee SY, Bender D, Ruiz RE. Development of a word recognition instrument to test health literacy in dentistry: the REALD-30-a brief communication. J Public Health Dent 2007; 67(2):94-8. 21. Vann WF Jr, Lee JY, Baker D, Divaris K. Oral Health literacy among female caregivers: Impact on oral health outcomes in early childhood. J Dent Res 2010;89:1395400.

22. Schroth RJ, Brothwell DJ, Moffatt ME. Caregiver knowledge and attitudes of preschool oral health and early childhood caries (ECC). Int J Circumpolar Health 2007; 66(2):153-67.

23. Bridges SM, Parthasarathy DS, Wong HM, Yiu CK, $\mathrm{Au}$ TK, McGrath CP. The relationship between caregiver functional oral health literacy and child oral health status. Patient Educ Couns 2014;94(3):411-6.
24. S Parthasarathy D, Bridges SM, McGrath CP, Au TK, Wong HM, Yiu CK. The Relation between Caregivers' Multi literate Reading Habits and Their Children's Oral Health Status. Interact J Med Res 2014 Sep 18; 3(3):e13. 25. Veerasamy A, Kirk RC. Oral health literacy of parents of pre-schoolers in New Zealand. Journal of theory and practice of dental public health 2013;1(4):209 .

26. Jones M, Lee JY, Rozier RG. Oral health literacy among adult patients seeking dental care. J Am Dent Assoc 2007; 138(9):1199-208.

27. Miller E, Lee JY, De Walt DA, Vann WF Jr. Impact of Caregiver Literacy on Children's Oral Health Outcomes. Pediatrics 2010; 126(1):107-114.

28. Lee JY, Divaris K, Baker AD, Rozier RG, Lee SY, Vann WF Jr. Oral health literacy levels among A Low-Income WIC population. J Public Health Dent 2011; 71:152-6o.

Source of support: Nil, Conflict of interest: None declared

Cite this article as:

Prakash D, Murthy AK, Paul A, Eremba K, Gupta G, Alex P. Oral Health Literacy among

Caregivers in Bangalore City, India. Int Healthc Res J. 2019;3(3):116-122. doi: https://doi.org/10.26440/IHRJ/0303.06243

\section{$\frac{\text { AUTHOR AFFILIATIONS: }}{1 .}$}

Senior Lecturer, Department of Public Health Dentistry, The Oxford Dental College, Bangalore (Corresponding Author)

Professor and HOD, Department of Public Health Dentistry, The Oxford Dental College, Bangalore

Senior Lecturer, Department of Public Health Dentistry, KMCT Dental College, Kerala

Senior Lecturer, Department of Public Health Dentistry, JNIMS Dental College, Imphal, Manipur

Senior Lecturer, Department of Public Health Dentistry, RKDF Dental College and Research Centre, Bhopal

Senior Lecturer, Department of Public Health Dentistry, EDUCARE Dental College, Kerala 